\title{
AUTODOCUMENTOS HISPANOAMERICANOS DEL SIGLO XIX. FUENTES PERSONALES Y ANÁLISIS HISTÓRICO
}

\section{Catherine AristizÁbal}

Berlín, 2012, Lit Verlag, 193 páginas.

ISBN: 978-3-643-11685-7

El estudio de las fuentes personales -documentos personales como definiera en su momento uno de los pioneros de esta línea de investigación el sociólogo de la Universidad de Essex Ken Plummer-, se ha convertido hoy en día en una de las modalidades que más intensidad y resultados está ofreciendo en los estudios sobre la historia social. En este sentido, esta fuente de investigación consolida, no sólo una clara alternativa a los documentos oficiales y públicos, frecuentemente mediatizados por el protocolo y el rigor, sino que además interesan a otros núcleos sociales que no son, precisamente, los detentadores de los resortes del poder, y no por ello menos fundamentales en el balance y en la interpretación histórica.

La historiadora Catherine Aristizábal, ubicada en la Universidad alemana de Hamburgo y especializada en el siglo XIX hispanoamericano, nos ofrece este libro que viene a ser, entre otros objetivos, un ágil y sintético estado de la cuestión sobre los diversos frentes posibles que estas fuentes íntimas e individuales, dan juego en la valoración que el investigador hace de éstas para hacer e interpretar la historia. Un intento de "realizar un balance y una clasificación adecuada de los tipos de fuentes personales durante el periodo mencionado", que no es otro que el ámbito antes mencionado.

Efectivamente y tras hacer una breve introducción conceptual en el que da juego con las expresiones "egodocumentos" "autodocumentos", tomado de algunos de los exponentes más sobresalientes del panorama historiográfico europeo del siglo anterior Schulze, Rutz, von Greyerz-, y desde el paraguas del grupo de investigación interdisciplinar de la Universidad Libre de Berlín "Autodocumentos desde una perspectiva transcultural”, Aristizábal arremete en su estudio a más de un centenar de autodocumentos hispanoamericanos localizados en la Biblioteca del Instituto Iberoamericano en Berlín en donde, apoyada por los matices y definiciones de especialistas logra estructurar, a nuestro parecer una afortunada clasificación de estas fuentes, que no sólo clarifica el entendimiento per se al que simplemente se acerca al estudio como lector interesado, sino que además ofrece una 
cuantiosa ayuda al investigador que precisa de unos rudimentos iniciales para adentrarse en esta modalidad en el estudio de la ciencia social.

De esta manera, se verifican seis grandes categorías de clasificación: Autobiografías, Memorias, Diarios personales, Diarios de viaje, Diarios de Campaña y escritura femenina.

Sobre las autobiografías, clarifica la conveniencia de definirla como un relato personal que va a caballo entre los elementos externos y oficiales, y los más intimistas del propio protagonista del relato. Un término que nos lleva a la inevitables comparativa del concepto de "biografía interna" que culminara con los atinados trabajos del intelectual Gregorio Marañón en torno a personajes como Antonio Pérez o el Conde Duque de Olivares. Un "pacto de la verdad" donde se suma lo personal, lo existencial y hasta lo psicológico, en unos exponentes que la autora enumera en algunos ejemplos como el político mexicano José Miguel Guridi y Alcocer o el colombiano José Rogelio Castillo.

Las memoria en cambio, se refieren a relatos de personajes con evidente notoriedad, pero donde preferencia su protagonismo o participación en acontecimientos externos lo suficientemente relevantes, que hace a su vez que las percepciones personales o íntimas queden claramente relegadas a la epopeya de los hechos. Una especie de testigo, de reportero del momento que se convierte en un hombre público y que no dura más del tiempo de sus propias responsabilidades públicas, como sucede con el argentino Tomás de Iriarte o el militar paraguayo Silvestre Aveiro.

Los diarios personales se centran más en un concepto de dato o anotación diaria o periódica, donde las interpretaciones son momentáneas, como verifican los ejemplos del chileno Fanor Velasco o el escritor mexicano Federico Gamboa. En este grupo, lo íntimo y lo público pueden ir de la mano, a la vez que lo familiar, lo rutinario o lo consuetudinario. Quizás, el hecho de que a veces, estos documentos puedan ser realizados con el pensamiento de que algún día fueran publicados, pudiera restarle espontaneidad y agrandar la objetividad y la compostura.

En cuanto a los diarios de viaje anotar su carácter descriptico, detallista, pormenorizado, en donde la libertad de impulsos e instintos suele ser más libre que en otro tipos de documentos personales. Pero tampoco olvidamos que en ellos se puede reflejar la trascendentalidad, la identidad nacional (posible crítica hispanoamericana al "vecino del norte"), los principios políticos o la nostalgia a los pasados culturales, como tienen botón de muestra los casos de José Hilario López, Estanislao Ceballos o Francisco Moreno. 
Los diarios de campaña ofrecen una preciosa y precisa información sobre las luchas militares, las actividades de tropa, el estado de ánimo, los sentimientos, y hasta los pormenores del día a día. Realizados casi siempre por soldados, a la falta de estilo y dimensión estilística le compensa los cuantiosos elementos e información, que pueden resultar útiles para una información que interese a determinadas investigaciones sobre los acontecimientos. Algunos referentes lo encontramos en los de famoso líder cubano Máximo Gómez o su compatriota Fermín Valdés.

Una última clasificación es la que suponen la llamada "escritura femenina", donde la autora vincula de manera necesaria con las corrientes de Género e Historia. En su caso, localiza tres diarios íntimos, tres memorias autobiográficas y un diario de viaje, en donde destaca sobremanera el protagonismo de la argentina Manuela Gorriti.

El bloque final, consistente en un listado comentado de cada uno de los documentos estudiados y clasificados, culminan un trabajo que a nuestro parecer, resulta útil y actual en torno a esta dinámica línea de investigación de las ciencias sociales en el marco espaciotemporal de la Hispanoamérica del siglo XIX.

José Marchena Domínguez

Universidad de Cádiz 